\title{
Workload Indicators of Staffing Need Method in Determining Anesthesia and Surgical Technologist Staff in Operating Room
}

\section{Rahim Khodayari-Zarnaq}

Tabriz University of Medical Sciences

\section{Reza Aghebati Maleki}

Tabriz University of Medical Sciences

\section{Zahra Mafakheri}

Tabriz University of Medical Sciences

Niosha Bozorghpour

Tabriz University of Medical Sciences

\section{Esmaeil Ezzati}

Tabriz University of Medical Sciences

\section{Rona Bahreini ( $\nabla$ bahreiny6886@gmail.com )}

Tabriz University of Medical Sciences https://orcid.org/0000-0002-9940-9468

\section{Research}

Keywords: Workload Indicators of Staffing Need (WISN), Anesthesia technologist, Surgical technologist, Operating room, Iran

Posted Date: December 31st, 2020

DOI: https://doi.org/10.21203/rs.3.rs-136794/v1

License: (c) (1) This work is licensed under a Creative Commons Attribution 4.0 International License. Read Full License 


\section{$4 \quad$ Abstract} (WISN).

2

\section{Workload Indicators of Staffing Need method in determining Anesthesia and Surgical Technologist Staff in Operating Room}

Background: Human resources in health are limited, and a variety of healthcare services are increasing, especially in developing countries. This study aimed to determine the anesthesia and surgical technologist staff for operating room based on the Workload Indicators of Staffing Need

Methods: This cross-sectional descriptive study was conducted at Shahid Madani Medical and Training Hospital in 2019. The data collected through interview and hospital documents observation. The WISN method was used to analyze and determine staffing need.

Results: The WISN ratio for anesthesia and surgical technologist staff were 1.60 and 4.94, respectively. In other words, in both categories, this ratio is $>1.00$.

Conclusions: WISN results can used to assess staffing capacity and capability over the previous year and the policy and financial implications due to staff shortages or surplus. As the workload of staff is an important issue and the staff have a right to have a standard workload in their position, then determining this workload is an essential issue in healthcare organization. Also, WISN method work as a human resource management tools, it improvers health managers to make right decision about staffing needs and then better manage of organization's resources.

Keywords: Workload Indicators of Staffing Need (WISN); Anesthesia technologist; Surgical technologist; Operating room; Iran 


\section{Background}

33 Human resources (H.R.) are the most important asset of the health system's effectiveness and

34 efficiency. They play a very important role in running and delivering health care in hospitals(1).

35 H.R. could also play a leading role in promoting the reconciliation of human rights and human 36 resource objectives and practices in organizations(2). Organization without adequate or 37 competence staffs is impossible to achieve its optimum performance $(1,3)$. With a numerous of 38 problems and reducing resources, the need to optimize utilization of the available resources is 39 critical(4). On the other hand, the over-supply of these resources also creates major problems, especially in terms of costs imposed on the health system(5). As a result, this issue is giving rise

41 to the cost of provision of health care services(6). In low-income countries health workforce 42 shortages has been identified as one of the main challenges of health(7). How to plan and 43 manage human resources for health is essential in ensuring good quality healthcare and the 44 sustainability of healthcare systems(8).Due to the nature of the health system, the lack of 45 attention to the number of manpower required in hospital wards affects the efficiency and 46 effectiveness of services(6). The operating room is one of the most complex work environments 47 in the hospital that plays a major role in care activities(9). The calculation of the exact needs of 48 the number of health workforce can support hospital labor productivity(1).

49 Human resources planning are the process by which organizations determine the amount of 50 employees based on place, skills, and behaviors needed to achieve their goals(1, 3).In this regard, 51 the most important step is to determine the current supply of forces and then predict the number 52 of cases needed in the future to identify existing gaps and subsequent corrective planning $(5,10)$.

53 Oftentimes, inappropriate uses of health personnel in inappropriate proportions leads to 
54 inadequate fulfill the resources required to the demand for services by the population(11). These

55 imbalances lead to spending too much time on activities requiring little time(12). Estimating the

56 number of human resource required is a necessary and inevitable step for hospital managers and

57 officials(6).In this regard, one of the scientific, practical and at the same time simple methods

58 which was first introduced by the World Health Organization in the field of health, is the

59 workload indicator of staffing need (WISN)(1, 5).

60 Worldwide, various methods and models have been designed and used to estimate health

61 manpower. The WISN method in attempt to address the human resource constraints was

62 developed by Shipp in 1998 and made popular by the WHO. This method computes the number

63 of health cadres required, based on the workload of a particular health facility $(12,13)$. Managers

64 can use WISN findings to planning and projection of human resources for health that helps to

65 determining appropriate levels of health $\operatorname{staff}(4,12)$. Most of these methods rely on the current

66 supply of forces and do not pay attention to the type of service provided and the necessary time

67 for it(5). WISN results can be used in the determination of staffing norms and standards, to

68 estimate the size of the staffing deficit or surplus, to assess the workload pressure of health

69 workers and staffing capacity and capability(10). The WISN method as a complete and

70 comprehensive human resource management tool can help to determining the optimal number

71 and distribution of health workforce at health facilities at all levels(8).

72 Ghorbani et al (2019) findings, 40 standard nurses were calculated. The studied hospital had 4 73 nursing staff shortages. The working pressure ratio is 0.91 in this study. In the current study, the 74 nursing staff shortage is observed and this shortage caused a high working pressure on the nurses 75 working in the study area. Considering the vital role of nurses in the emergency department, it is 76 recommended to employ and distribute the manpower based on the requirement and workload in 
77 the department(14). The purpose of study of Noprianty et al (2020) was to determine the analysis

78 of the needs of nurses based on the WISN method. The results showed that the need for nurses is

7928 people, while which are available is 24 nurses, with the WISN Ratio result, it is found that 0.8

80 is less than 1 . The results of this study can be taken into consideration in reducing the number of

81 nursing staff in the morning shift and added the afternoon shift(15).Based on the research Joarder

82 and et al (2020) assessed the current workload and staffing need of physicians and nurses for

83 delivering optimum healthcare services at the Upazila Health Complexes (UpHCs) in

84 Bangladesh. Physicians have very high (WISN ratio 0.43) and nurse high (WISN ratio 0.69)

85 workload pressure. $50 \%$ of nurses' time is occupied with support activities, instead of nursing

care. There are different workloads among the same staff category in different health facilities. If

87 only the vacant posts are filled, the workload is reduced. In fact, sanctioned number of

88 physicians and nurses is more than actual need(16).

89 For a variety of reasons, including a lack of funding for employment, a lack of employment

90 licenses in some occupations, and a lack of proper use of hospital bed capacity, these hospitals

91 often do not comply with the Ministry of Health's human resource standards(3).The application

92 of appropriate, scientific and logical methods in estimating the required human resources not

93 only leads to productivity and employee satisfaction, but also maintains the quality of services

94 provided(5). The WISN approach allowed us by measuring the demand and supply improve 95 many types of decisions regarding health workforce planning and management(10). WISN 96 method can aid the policy-makers in optimizing utilization of existing human resources. Given 97 the importance of human resource planning, the purpose of this paper was to use the WISN 98 method to calculate the number of anesthesia and surgical technologist staff. 
100

101

102

103

104

105

106

107

108

109

110

111

112

113

114

115

116

$117 \mathrm{~B}=$ the number of days off for annual leave in a year

$118 \mathrm{C}=$ the number of off-duty days due to sickness

$119 \mathrm{D}=$ the number of public holidays

$120 \mathrm{E}=$ the number of off-duty days due to other leaves (such as training, etc).

$121 \mathrm{~F}=$ the number of work time

\section{Methods}

\section{Step 1: Available Working Time (AWT)} account authorized and unauthorized absences.

$\mathrm{AWT}=[\mathrm{A}-(\mathrm{B}+\mathrm{C}+\mathrm{D}+\mathrm{E})] \times \mathrm{F}$

A = working hours per month

We conducted a cross-sectional descriptive study in the operating room of the Shahid Madani Medical and Training Hospital. This study was conducted using the WISN methodology that was recommended in 1998 by the WHO. This method calculates actual and (required) number of personnel with the workload of a given health facility and shows the level of staff shortage or surplus. Population in this study was the entire anesthesia cadre. Data were collected through structured interviews and by reviewing annual service statistics from each hospital' s records. The structured interviews included available staff time, workload components (i.e. Health Service Activities, Support and Additional Activities) and staff time spent on each activity (i.e. Activity Standards).Based on the WISN user's manual the method steps are described as follows:

AWT is the time a health worker has available in one year to do his/hers work; taking into 
123

124 Workload components include health services, support and additional activities, i.e. work 125 activities that take up most of a health worker's daily working time.

126

127

128

129

130

131

132 133 134 135 136 137 138

139 Standard workload $=\frac{\text { Available Working Time }}{\text { Activity Standard }}$

The standard workload is the amount of work within a health service workload component that one health worker can do in a year. This was calculated using the formula;

\section{Step 5: Allowance factors}

143 Allowance standards are in 2 types: 
144 Category allowance standards (CAS): Support or additional activities performed by all members

145 of the staff cadre.

146 Individual allowance standards (IAS): Support or additional activities performed by certain

147 members of the staff cadre activities.

148 Allowance factors are two types of factors as category and individual allowance factors.

149 The category allowance factor (CAF) is a multiplier that is used to calculate the total number of 150 health workers, required for support and health service activities.

$151 \quad \mathrm{CAF}=\frac{1}{1-\sum \mathrm{CAS} \%}$

152 The individual allowance factor (IAF) is the staff requirement to cover additional activities of 153 certain cadre members.

$154 \quad \mathrm{IAF}=\frac{\mathrm{IAS}}{\mathrm{AWT}}$

155

156 Step 6: Workload-Based Staffing Requirements

157

158 WISN staff requirement $=\left[\frac{\text { Annual workload } \times \text { CAF }}{\text { Standard workload }}\right]$

159

$160 \quad$ Step 7: Analysis and interpretation of results

161 The seventh step is the analysis and interpretation of the above results.

162 
163

164

165

166

167

168

169

170

171

\section{Results}

173

174 The present study applied WISN method in determining staffing requirements for anesthesia and 175 operating room cadre. Based on the formula $[\mathrm{A}-(\mathrm{B}+\mathrm{C}+\mathrm{D}+\mathrm{E})] \times \mathrm{F}$, the $\mathrm{AWT}$ for cadres was 176 calculated and estimated to be 1575.According to the results, 9 duties were recognized as the 177 components of the main activity for anesthesia. Working hours per month (A) is 365 ; B is 15 , the 178 number of days off for annual leave in a year; $\mathrm{C}$ is 3.5, the number of off-duty days due to 179 sickness; $\mathrm{D}$ is 78 , the number of public holidays; $\mathrm{E}$ is 6 , the number of days off due to other 180 leave; and $\mathrm{F}$ is 6 , the number of work time. Table 1 presents the main activities, the working time 181 and the standard workload of each health service activity for both cadres.

182 The findings show that the number of anesthesia and surgical technologist staff required 183 performing the main activities and care in the operating room based on the formula $184 \frac{\text { Total statistics in } 2018}{\text { Standard workload }}$ is 7.1 and 3.44 people, respectively (Tables 1 and 2).

\section{Data analysis and interpretation}

The results analyzed using two ways, the difference and the ratio. The first way is comparing the "Difference" between current and required staffing levels. This difference identifies understaffing or overstaffing. By using the WISN ratio can assess the work pressure of health workers in daily work. If the ratio is $>1$, there are additional personnel and if it is $<1$, there is personnel shortage. Whatever it is lower than one, the working pressure is higher. This step was also performed in Excel using the results of previous steps. 
Talle1. Estimate the required number of anesthesia staff based on the main activities

\begin{tabular}{|c|c|c|c|c|}
\hline Main activities & Unit time & Standard workload & $\begin{array}{c}\text { Total } \\
\text { statistics in } \\
2018\end{array}$ & $\begin{array}{c}\text { Estimated } \\
\text { number of } \\
\text { staff }\end{array}$ \\
\hline $\begin{array}{c}\text { Ensuring the operation and efficiency of anesthesia } \\
\text { devices and equipment }\end{array}$ & $2 \mathrm{~min} /$ operation & $3 \times 1575=47250$ & 2054 & 0.04 \\
\hline $\begin{array}{l}\text { Preparation of drugs required for existing anesthesia } \\
\text { facilities according to the type of operation and the } \\
\text { patient's age }\end{array}$ & 15 min/operation & $4 \times 1575=6300$ & 2054 & 0.32 \\
\hline $\begin{array}{l}\text { Control the patient's name with a clear list of } \\
\text { operations and files and bracelets }\end{array}$ & 10 min/operation & $6 \times 1575=9450$ & 2054 & 0.21 \\
\hline $\begin{array}{l}\text { Explain the anesthesia process and do some routine } \\
\text { things like sticking glue }\end{array}$ & 3 min/operation & $20 \times 1575=31500$ & 2054 & 0.06 \\
\hline Intravenous administration & 2 min/operation & $30 \times 1575=47250$ & 2054 & 0.04 \\
\hline Transfer the patient to the ICU & 3 min/operation & $20 \times 1575=31500$ & 2054 & 0.06 \\
\hline Collaboration in VF cardiopulmonary resuscitation & 4 min/operation & $15 \times 1575=23625$ & 2054 & 0.08 \\
\hline Collaboration in BLF cardiopulmonary resuscitation & $20 \mathrm{~min} /$ operation & $3 \times 1575=4752$ & 2054 & 0.43 \\
\hline $\begin{array}{l}\text { Anesthesia administration during surgery until surgery } \\
\text { is completed }\end{array}$ & $270 \mathrm{~min} /$ operation & $0.22 \times 1575=350$ & 2054 & 5.86 \\
\hline Total & & & & $7 / 1$ \\
\hline
\end{tabular}

188 
TaBle2. Estimate the required number of surgical technologist staff based on the main activities

\begin{tabular}{|c|c|c|c|c|}
\hline Main activities & Unit time & Standard workload & $\begin{array}{l}\text { Total } \\
\text { statistics in } \\
2018\end{array}$ & $\begin{array}{c}\text { Estimated } \\
\text { number of } \\
\text { staff }\end{array}$ \\
\hline $\begin{array}{l}\text { Communicating and providing the } \\
\text { necessary training to the patient and } \\
\text { prepare mentally and physically }\end{array}$ & $5 \mathrm{~min} /$ operation & $12 \times 1575=18900$ & 2054 & 0.1 \\
\hline $\begin{array}{l}\text { Controlling the patient's name with a } \\
\text { specific file and bracelet and place all } \\
\text { devices and equipment around the surgical } \\
\text { bed according to accessibility }\end{array}$ & $20 \mathrm{~min} /$ operation & $3 \times 1575=4725$ & 2054 & 0.4 \\
\hline $\begin{array}{l}\text { Helping surgeons and scrubs in wearing } \\
\text { gown and gloves }\end{array}$ & $10 \mathrm{~min} /$ operation & $6 \times 1575=9450$ & 2054 & 0.21 \\
\hline $\begin{array}{c}\text { Washing hands according to the } \\
\text { instructions }\end{array}$ & 5 min/operation & $12 \times 1575=18900$ & 2054 & 0.1 \\
\hline Covering the patient with sterile covers & $10 \mathrm{~min} /$ operation & $6 \times 1575=9450$ & 2054 & 0.21 \\
\hline $\begin{array}{l}\text { Participating in cardiovascular } \\
\text { resuscitation operations in the operating } \\
\text { room }\end{array}$ & $20 \mathrm{~min} /$ operation & $3 \times 1575=4725$ & 2054 & 0.43 \\
\hline $\begin{array}{c}\text { Unpacking primary covers, sterling } \\
\text { packages, yarns and other devices and } \\
\text { providing a safe area }\end{array}$ & $30 \mathrm{~min} /$ operation & $2 \times 1575=3150$ & 2054 & 0.65 \\
\hline $\begin{array}{l}\text { Counting and recording yarn, gas, etc. } \\
\text { before finishing with the surgical team and } \\
\text { collecting them after use }\end{array}$ & $15 \mathrm{~min} /$ operation & $4 \times 1575=6300$ & 2054 & 0.32 \\
\hline $\begin{array}{c}\text { Helping with surgical dressings and control } \\
\text { the observance of sterile tips during } \\
\text { surgery }\end{array}$ & 5 min/operation & $12 \times 1575=18900$ & 2054 & 0.1 \\
\hline $\begin{array}{l}\text { Removing the covers and prepare the } \\
\text { patient for transfer to the ICU and remove } \\
\text { the equipment related to the previous } \\
\text { surgery and prepare the room for the next } \\
\text { operation. }\end{array}$ & $30 \mathrm{~min} /$ operation & $2 \times 1575=3150$ & 2054 & 0.6 \\
\hline Assisting in moving the patient to the ICU & $15 \mathrm{~min} /$ operation & $4 \times 1575=6300$ & 2054 & 0.32 \\
\hline \multicolumn{4}{|c|}{ Total } & 3.44 \\
\hline
\end{tabular}

202 Similarly, working time for support and additional activities, (i.e. category allowance standards,

203 individual allowance standards, category allowance factor and individual allowance factor,

204 respectively), was recorded as demonstrated in Tables 3-6. These data were calculated based on

205 the formulas mentioned in the fifth step of WISN. 
TQBle3. Estimation of time spent on support activities for anesthesia staff

\begin{tabular}{cccc}
\hline $\begin{array}{c}\text { Support } \\
\text { Activities }\end{array}$ & CAS & CAS \% & CAF \\
\hline $\begin{array}{c}\text { Written and oral report of the } \\
\text { patient's latest condition (vital signs, } \\
\text { anesthesia, medications, level of } \\
\text { consciousness, skin color, etc.) to } \\
\text { the ICU nurse and the patient's } \\
\text { connection to the monitoring system } \\
\text { Participate in an internal conference }\end{array}$ & An minutes a day & $10 \div 60=0.16$ & $1 \div(1-4.12 \%)=1.04$ \\
Participate in monthly training & Two hours a month & $(2 \times 12) \div 1575 \times 100=1.25$ \\
Total CAS\% & & $4.12 \%$ & $(1 \div 36) \times 100=2.7$ \\
\hline
\end{tabular}

210

Table4. Estimation of time spent on support activities for surgical technologist staff

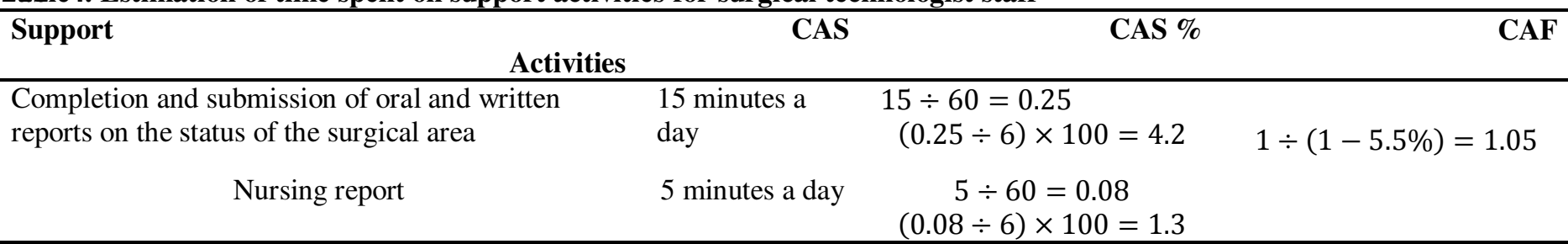

212

213ble5. Estimation of Individual Allowance Standards for anesthesia staff

\section{Additional Activities}

Requesting anesthesia defects such as

medicine, equipment and ...

Writing a monthly schedule

IAS

Two hours a week

6 hours a month

\section{Annual IAS}

$2 \times 52=104$

$6 \times 12=72$

Total IAS

$104+72=176$

$2 \overline{14}$

215ble6. Estimation of Individual Allowance Standards for surgical technologist staff

\begin{tabular}{cccc}
\hline Additional Activities & IAS & Annual IAS & IAF \\
\hline $\begin{array}{c}\text { Participating in meetings, seminars, } \\
\text { conferences }\end{array}$ & 45 minutes a week & $(45 \div 60) \times 52=39$ & $176 \div 1575=0.11$ \\
Intra-departmental meetings & 90 minutes a month & $(90 \div 60) \times 12=18$ & \\
Total IAS & & $18+39=57$ & \\
\hline
\end{tabular}

218 After obtaining the required data, the required number of human resources for both categories of

219 staff was estimated to be 7.49 and 3.64, respectively using the relevant formula. The WISN 
220 calculation was based on the annual workload data for 2018/2019 fiscal year. The WISN ratio

221 was obtained by dividing the existing staff by the total required staff expressed as a percentage.

222 The calculated number for anesthesia staff (7.49) is for the total of 6 operating rooms. There are

2232 anesthesia forces in each operating room, and our calculated number is 7.49 for the total of 6

224 operating rooms, it indicates that approximately 8 staff members are required to cover 6

225 operating rooms. In addition, operations performed in all 6 operating rooms are usually

226 performed simultaneously. Therefore, in ideal conditions, one anesthesia staff (n=6) with 2

227 auxiliary staff to support operating rooms is sufficient for each operating room.

228 The calculated number for surgical technologist staff (3.64) is for the total of 6 operating rooms.

229 There are 3 surgical technologists in each operating room that indicates approximately 4 staff

230 members are required to cover 6 operating rooms. Therefore, in ideal conditions, one surgical

231 technologist for each operating room $(n=6)$ to support operating rooms is sufficient.

232 According to our results, if the WISN ratio for both categories of staff is $>1.00$, the staff is more

233 than sufficient to cope with the workload (Tables 7 and 8).

Taßle7. Existing staffing levels and staff required for anesthesia staff

\begin{tabular}{ccccc}
\hline Cadres & $\begin{array}{c}\text { Exiting number of } \\
\text { staff at 2019 }\end{array}$ & $\begin{array}{c}\text { WISN Staff } \\
\text { required }\end{array}$ & $\begin{array}{c}\text { Existing gap as } \\
\text { at 2018/2019 }\end{array}$ & WISN ratio \\
\hline Anesthesia staff & $2 \times 6=12$ & $(7.1 \times 1.4)+0.11=7.49$ & $12-7.49=+4.51$ & $12 \div 7.49=1.60$ \\
\hline 235 & & & &
\end{tabular}

Table8. Existing staffing levels and staff required for surgical technologist staff

\begin{tabular}{cccc}
\hline Cadres & $\begin{array}{c}\text { Exiting number of } \\
\text { staff at 2019 }\end{array}$ & $\begin{array}{c}\text { WISN Staff } \\
\text { required }\end{array}$ & $\begin{array}{c}\text { Existing gap as } \\
\text { at 2018/2019 }\end{array}$ \\
\hline $\begin{array}{c}\text { surgical technologist } \\
\text { staff }\end{array}$ & $3 \times 6=18$ & $(3.68 \times 1.07)+0.3=3.64$ & $18-3.64=+14.36$ \\
\hline 237 & & & $18 \div 3.64=4.94$ \\
\end{tabular}




\section{$241 \quad$ Limitations}

242 The results of this study cannot be generalized because the varying quality and quantity of 243 service delivery. Some service statistics data, which were essential for establishing standard 244 workloads, were not readily available due to research in the operating room that requires special 245 conditions. Thus, the accuracy of this study's results is directly depends on the accuracy of the 246 service statistics of each hospital.

Discussion

250 The present study showed that due to the volume of work in the operating room of the hospital 251 and the time spent for the relevant activities, 8 anesthesia staff and 4 surgical technologist staff is 252 needed, which currently 12 and 6 people are working in this ward, respectively. Therefore, 253 according to the calculations, there is an excess of force. There are also studies where have 254 evaluated the required number of staff in the variety wards of hospital with this method.

255 The workload and human resource requirement were evaluated in a study conducted in 256 Pharmacy Installation of Santa Maria Hospital Pekanbaru 2017, and it was concluded that total 257 requirement of pharmaceutical work force during effective day is 40 persons, while requirement 258 during holiday accounted for 21 persons and make it totally 61 persons. Therefore, an additional 259 required seven people to cope with the workload at the Pharmacy unit of Santa Maria 260 Hospital(17).

261 The World Bank has instituted a WISN Study in 75 Health Facilities of Malawi targeting 8 262 priority health cadres. WISN analysis indicated that staff in the Northern Zone is working under 
263 greatest workload pressure with Medical Officers and Clinical Technician under greatest 264 pressure. In the Central East Zone there were no Medical Officers, Nursing Officers, Pharmacy 265 technicians, and Laboratory Technicians posted to the facilities targeted in the study 266 consequently the remaining four cadres were under extreme workload pressure. Similarly, the 267 Central West Zone has high pressure having only $20 \%$ of Medical Officers, Nurse Midwife 268 Technicians, Laboratory Technicians and Medical Assistants required(18).

269 Another study analyzed the real needs of nurses on staff WISN. The results obtained based on 270 the calculation of nurses with WISN method indicated required number of nurses in the medical271 surgical nurses as many as 54 people. This study concluded the number of nurses in the medical272 surgical general hospital Bali is still lacking as many as 30 people. It is suggest to the hospital 273 management to increase gradually the number of nurses in the medical room(19).

274 Prytherch et al. (2019) concludes that there is an oversupply of doctors and nurses at primary 275 health care (PHC) and a shortage of family doctors working at the level of health centers. 276 Consequently, a more rational health workforce planning based on well-grounded methodology 277 such as WISN has potential to contribute to more efficient and effective health service delivery 278 in Tajikistan(20).

279 Study was conducted to assess the current workload and staffing need of physicians and nurses 280 for delivering optimum healthcare services at the Upazila Health Complexes (UpHCs) in 281 Bangladesh. Physicians have very high (WISN ratio 0.43) and nurse high (WISN ratio 0.69) 282 workload pressure. In fact, sanctioned number of physicians and nurses is more than actual need. 283 It is evident that high workload pressures prevail for physicians and nurses at the UpHCs. This 284 reveals high demand for these health workforces in the respective sub-districts(16). 
285 The WISN tool was used in assessing the staffing requirements of the frontline health workforce 286 for select primary level facilities in Rivers State in Nigeria. Findings showed Health facilities in 287 Port Harcourt City Local Government Area (PHALGA) had a WISN ratio of 0.63 and a shortage 288 of 31 nurses/midwives. There was also a shortage of 12 community health practitioners with a 289 WISN ratio of 0.85 . ObioAkpor Local Government Areahad (OBALGA) a shortage of 50 290 nurses/midwives and 24 community health practitioners; and WISN ratios of 0.60 and 0.79 for 291 nurses/midwives and community health practitioners respectively(21).

292 The study was conducted by Farahi Shahgholi aimed to calculation of workload and estimation 293 of the required number of health staff related to family medicine program in East Azerbaijan 294 province based on WISN. The results showed that significant obligations for 25000 populations 295 were consisted of family health services (0.87), prevention of disease (1.067), health schools and 296 health education (0.105). In total, 2.042 health care staffs should be recruited for providing 297 health care services for 25000 populations. Proportion of extraordinary health services and 298 coefficient of extraordinary health services were estimated $24.1 \%$ and $\% 1.32$ respectively(22).

299 WISN was utilized to analyze and determine the requirement of nurses for a high volume 300 academic Emergency Department. The WISN ratio was 0.90 which indicates that the current 301 staff strength was inadequate. The Emergency Department requires 13 more full time staff nurses 302 for it to function optimally. In case of reallocation of certain relevant duties to phlebotomists or 303 nursing assistants, the requirement of staff nurses is 102 . Consequently, a skill mix ratio of $82 \%$ 304 nurses to $18 \%$ nursing assistants and phlebotomists is suggested(23). 
305 The results of WISN ratio can be used in all health facilities and all types of health staff to 306 estimate the requirement number of staff based on the workload. Also, these calculations can be 307 used to review staffing levels and workload pressures(24).

\section{$308 \quad$ Recommendations}

309 Similar studies are required at different job categories in order to determine the shortage or extra 310 of staff and the possibility of comparison with similar groups in other hospitals. Findings also 311 help to conduct of WISN study at a larger scale and inclusion of WISN as a tool to improving 312 quality of care. Our findings proposed reallocation of staff based on workload in order to avoid 313 wasting resources.

\section{Conclusions}

315 Human resource management and planning is a big challenge, especially in developing countries.

316 On the other hand, resources for the health sector are scarce and demand is increasing instead.

317 The WISN method is a simple, easy to calculate the requirements of hospital ward staff. This 318 method is also useful to identify staffing inequities between facilities by comparing the 319 calculation results. Such an analysis can also help to assess distribution of staffing between 320 similar types of health facilities in order to estimate the size of the staffing deficit or surplus. 321 More importantly, the WISN tool allows policy-makers improving health workforce planning 322 and management. This study can aid the decision making about transfer and allocate functions 323 between categories of staff. Through the results of these calculations can be anticipated 324 workloads of planned future services, changed conditions of employment and health needs of the 325 population. Consequently, these results create an opportunity to get organizations to take greater 326 responsibility for human rights and go beyond just economic and legal motives for social reform. 
327 Also, results from our study can be contributed to evaluate imbalance (shortage and excess) and 328 improve the current operation of health services.

\section{$329 \quad$ List of abbreviations}

330 WISN: Workload indicators of staffing need; WHO: World health organization; AWT: Available 331 working time; AS: Activity Standard; CAS: Category allowance standards; IAS: Individual 332 allowance standards; CAF: Category allowance factor; IAF: Individual allowance factor; PHC: 333 Primary health care; UpHCs: Upazila Health Complexes; PHALGA: Port Harcourt City Local 334 Government Area; OBALGA: Obio Akpor Local Government Areahad.

\section{Declarations}

\section{Ethics approval and consent to participate}

Ethical approval such as explaining the purposes of the research, obtaining oral consent, keeping their information anonymous was obtained from the participating hospitals.

\section{Consent for publication}

$341 \quad$ Not applicable

\section{$342 \quad$ Availability of data and materials}

343 The datasets used and/or analyzed during the current study are available from the corresponding 344 author on reasonable request.

\section{Competing interests}

346 The authors declare that they have no competing interests. 


\section{Authors' contributions}

349 R.B. and R.K.Z. designed and directed the project. R.K.Z., R.B. and R.A.M. contributed to the 350 design and implementation of the research. Z.M., N.B. and E.E. performed the measurements, 351 processed the experimental data, and performed the analysis. R.A.M. contributed to the

352 interpretation of the results. R.B. drafted the manuscript. R.K.Z. and R.A.M. were involved in 353 planning and supervised the work.

\section{Acknowledgements}

355 The author would like to thank the operating room staff of Shahid Madani hospital that 356 contributed. This paper highlights findings from an undergraduate students' internship. Authors 357 appreciate all people who contributed in this study.

358 Authors' information

359 Rona Bahreini is healthcare services management $\mathrm{PhD}$ candidate in the School of Health 360 Management and Medical Informatics, Tabriz University of Medical Sciences, Tabriz, Iran. She 361 holds master's degree in healthcare services management at the School of Management and 362 Medical Informatics. Her current research interests are centered in the field of health 363 management, strategic planning, human resources management, systematic review and 364 qualitative study.

365 Dr. Rahim Khodayari-Zarnaq is Assistant Professor of Health Policy. His current research 366 interests are centered in the field of health policy, public policy, policy analysis and etc. 
367 Currently he is working as a Teacher in Department of Healthcare Services Management at 368 School of Management and Medical Informatics, Tabriz University of Medical Sciences.

369 Dr. Reza Aghebati Maleki is health policy PhD candidate in the School of Health Management 370 and Medical Informatics, Tabriz University of Medical Sciences, Tabriz, Iran. He is also a 371 graduate of General Medicine. His current research interests are centered in the field of health 372 policy, WISN method and etc.

373 Zahra Mafakheri is healthcare services management graduate with a bachelor's degree in the 374 School of Health Management and Medical Informatics, Tabriz University of Medical Sciences, 375 Tabriz, Iran.

376 Niosha Bozorghpour is healthcare services management graduate with a bachelor's degree in the 377 School of Health Management and Medical Informatics, Tabriz University of Medical Sciences, 378 Tabriz, Iran.

379 Esmaeil ezzati is healthcare services management graduate with a bachelor's degree in the 380 School of Health Management and Medical Informatics, Tabriz University of Medical Sciences, 381 Tabriz, Iran. 


\section{References}

1. Napirah MR, Sulistiani AO. Analysis of the optimal number of staff needed using workload indicator of staffing needed (WISN) method in laboratory unit of public hospital anutapura palu. Public Health of Indonesia. 2015;1(1).

2. Palthe J. Managing human rights and human resources: the dual responsibility of global corporations. Journal of Academic Perspectives Volume. 2010(3):1.

3. Shafii M, Sadat Hashemi F, Askari R, Pakdaman M, S B. Estimation of the required staffing capacity of selected hospitals in Yazd city, Iran, in accordance with staffing standards of Iranian Ministry of Health and Medical Education in year 2017. Health Information Management. 2019;16(2):57-64.

4. Musua P, Nyongesa P, Shikhule A, Birech E, Kirui D, Njenga M, et al. Workload indicators of staffing need method in determining optimal staffing levels at Moi teaching and referal hospital. East African Medical Journal. 2008;85(5):232-9.

5. Azimi Naibi B, Mohebbifar R, Rafiei S. Estimating the number of required nurses in an emergency department of a hospital in Qazvin: Application of WISN method. The Journal of Qazvin University of Medical Sciences. 2018;22(2):28-37.

6. Forati H, Mahdiyan Z. Survey of the causes and solutions to reduce defensive medicine in view of residents in mashhad university of medical sciences in 2016. 2017.

7. Hagopian A, Mohanty MK, Das A, House PJ. Applying WHO's 'workforce indicators of staffing need'(WISN) method to calculate the health worker requirements for India's maternal and child health service guarantees in Orissa State. Health policy and planning. 2012;27(1):11-8. 8. Gialama F, Saridi M, Prezerakos P, Pollalis Y, Contiades X, Souliotis K. The implementation process of the Workload Indicators Staffing Need (WISN) method by WHO in determining midwifery staff requirements in Greek Hospitals. 2019.

9. Christian CK, Gustafson ML, Roth EM, Sheridan TB, Gandhi TK, Dwyer K, et al. A prospective study of patient safety in the operating room. Surgery. 2006;139(2):159-73.

10. Shipp P, Organization WH. Workload indicators of staffing need (WISN): a manual for implementation. World Health Organization, 1998.

11. Kayani NS, Khalid SN, Kanwal S. A study to assess the workload of lady health workers in Khanpur UC, Pakistan by applying WHO's WISN method. Athens J Health. 2016;3:65-78.

12. Govule P, Mugisha JF, Katongole SP, Maniple E, Nanyingi M, Onzima R. Application of workload indicators of staffing needs (WISN) in determining health workers' requirements for Mityana general hospital, Uganda. International Journal of Public Health Research. 2015;3(5):254-63.

13. McQuide PA, Kolehmainen-Aitken RL, Forster N. Applying the workload indicators of staffing need (WISN) method in Namibia: challenges and implications for human resources for health policy. Human resources for health. 2013;11(1):64.

14. Ghorbani A, Vaziri Seta M, Rajaee R, Jamaly Z, Najafi M, Najafi M. Estimating required number of nurses in emergency department of Imam Ali hospital affiliated by Alborz province using WISN method. Evidence Based Health Policy, Management and Economics. 2019;3(4):250-8.

15. Noprianty R, Febianti SA, Fikri J. Analysis of nurses staff needs using workload indicate staff need in pediatric ward with time motion study. JMMR 2020;9(1):13-22. 
433 16. Joarder T, Tune SNBK, Nuruzzaman M, Alam S, de Oliveira Cruz V, Zapata T. 434 Assessment of staffing needs for physicians and nurses at Upazila health complexes in 435 Bangladesh using WHO workload indicators of staffing need (WISN) method. BMJ open. $436 \quad 2020 ; 10(2)$.

437 17. Susanto MN, Permanasari VY, editors. Staffing needs analysis in the pharmacy unit of 438 Santa Maria Hospital Pekanbaru 2017. Proceedings of the International Conference on Applied 439 Science and Health; 2018.

440 18. Mziray E, Gorgens M, McCauley P. Analysis of human resources for health in Malawi: 441 Implementation of WISN study in seventy-five facilities. World Bank; 2017.

442 19. Ernawati NLAK, Nursalam N, Djuari L. Kebutuhan riil tenaga perawat dengan metode 443 workload indicator staff need (WISN). Jurnal Ners. 2017;6(1):85-92.

444 20. Prytherch H, Kasymova Z, Lechthaler F, Kiefer S, Yarbaeva S, Hojimatova Z, et al. 445 Bringing greater transparency to health workforce planning in Tajikistan: using the WISN 446 approach. European Journal of Public Health. 2019;29(Supplement_4):ckz185. 616.

447 21. Okoroafor S, Ngobua S, Titus M, Opubo I. Applying the workload indicators of staffing 448 needs method in determining frontline health workforce staffing for primary level facilities in 449 Rivers state Nigeria. Global Health Research and Policy. 2019;4(1):35.

450 22. Farahi Shahgholi J, Nadrian H, K G. Calculation of workload and estimation of the 451 required number of health staff related to family medicine program in East Azerbaijan province 452 based on WISN. 2018.

453 23. Wundavalli LT, Kumar P, Dutta S. Workload indicators of staffing need as a tool to 454 determine nurse staffing for a high volume academic emergency department: An observational 455 study. International emergency nursing. 2019;46:100780.

456 24. Ekawati A. The analysis of workload and need of nurse with WISN method in inpatient 457 room in hospital X in Yogyakarta. JMMR. 2018;7(1):69-75. 